\title{
Liquid-Liquid Equilibrium Behavior and In Vitro Digestion Simulation of Medium Chain Fatty Acids
}

\author{
Ericsem Pereira, Antonio J. A. Meirelles, Guilherme J. Maximo
}

School of Food Engineering, University of Campinas, 80 Monteriro Lobato Street, 13083- 062 Campinas, Brazil

\begin{abstract}
The absorption of medium-chain fatty acids (MCFA) depends on the solubility of these components in the gastric fluid. Parameters such as the total MCFA concentration, carboxyl ionization level, and carbon chain length affect the solubility of these molecules. Moreover, the enzymatic lipolysis of solubilized triacylglycerol (TAG) molecules may depend on the carbon chain length of the fatty acids (FAs) components and their positions on the glycerol backbone. This present study aimed at investigating the effect of electrolyte usually formed during the gastric digestion phase on the solubility of MCFA, and evaluating the influence of the FA carbon chain length on the lipolysis rate during the in vitro digestion simulation. The results obtained here showed that the increasing of electrolyte concentrations tend to decrease the mutual solubility of systems composed by the caproic and caprylic fatty acids + sodium chloride, sodium bicarbonate, and potassium chloride solutions. We also observed that a conventional version of the thermodynamic UNIQUAC model was able to correlate the liquid-liquid phase behavior of the electrolyte solutions. Regarding the in vitro digestion simulation, the experimental data indicated that the action of the pancreatic enzyme occurred preferentially in TAG molecules comprised of short and medium-chain fatty acids.
\end{abstract}

Key words: Phase equilibrium; In vitro lipid digestion; Fats and oils. 


\section{Introduction}

The gastric lipolysis contributes to $10-30 \%$ of overall lipolysis of dietetic triglycerides, forming free fatty acids (FFA), mono- and diacylglycerols (MAG and DAG, respectively). During this process, the gastric lipolysis of triacylglycerol (TAG) molecules containing medium-chain fatty acids (MCFA) is more efficient than that of TAGs composed of long-chain fatty acids (LCFA) (Armand et al., 1999; Koziolek et al., 2018). However, the solubility of those triglyceride digestion products, such as FFA, is required for uptake and use by the body (Phan et al., 2015).

Such variables as total FA concentration, carboxyl group ionization level, carbonchain length, and temperature affect the solubility of FA molecules in the gastric solution (Cistola et al., 1988; Shiau, 1990; Toro-Vazquez et al., 1991). Moreover, the FA solubility depends on the electrolyte concentration, as well as the ingesta temperature. The FA diffusion-based transference is affected by the ionic strength of the mixture, since the FA solubility is inversely proportional to the electrolyte concentration (Ayala-Bribiesca et al., 2017; Charlton \& Smith, 1982). On the one hand, publications evaluating the concentration of calcium ions and their effects on the decreasing of LCFA availability to form mixed micelles and vesicles (Devraj et al., 2013), as well as sodium ions affecting the transport of FAs to a cellular level can be found elsewhere (Hofmann, 1976). On the other hand, study publications evaluating the correlation between the MCFA and gastric electrolyte concentrations are scarce.

Although the lipolysis mechanism, which takes place during the fats and oils digestion, is well known and registered in the literature (Mattson \& Volpenhein, 1964), fat emulsions formed during digestion behave differently, depending on their initial physio-chemical properties. For instance, while the stomach mediates the direct absorption of MCFA $(\mathrm{C}<12)$ through the gastric mucosa, LCFAs released in the stomach by digestion are the trigger to the secretion of hormones such as cholecystokinin, which mediate downstream food effects (Koziolek et al., 2018). Furthermore, the gastric lipolysis of TAG comprising MCFA is more efficient than that of TAG comprising LCFA since the latter does not dissociate from the lipid-water interface as readily as MCFAs rich TAG molecules.

In this context, in vitro gastrointestinal digestion simulation protocols have been widely used by several food science and nutrition research groups to understand the mechanism of food digestion, since conducting experiments with humans is generally 
time and money expensive, and often are involved in ethic disputes. Various in vitro digestion protocols have been developed to simulate the lipid digestion, which in the vast majority considers only the intestinal phase (Bakala-N'Goma et al., 2015; Barker et al., 2014; Williams et al., 2013). It is worth noting that the protocol developed by Minekus et al. (2014) proposed a standardized and practical in vitro static digestion method. This protocol is based on relevant physiological conditions, including the oral, gastric, and intestinal digestion phases.

Thus, this present study is aimed at: $i$ ) investigating the effect of electrolyte usually formed during the gastric digestion phase (potassium chloride $(\mathrm{KCl})$, sodium bicarbonate $\left(\mathrm{NaHCO}_{3}\right)$, and sodium chloride $\left.(\mathrm{NaCl})\right)$, on the solubility of MCFA; ii) evaluating the influence of the FA carbon chain length on the lipolysis rate during the in vitro simulation intestinal phase digestion of fats, oils, and pure TAG samples.

\section{Methodology}

\section{Material}

Liquid-liquid equilibrium behavior

The caproic (hexanoic acid) and caprylic (octanoic acid) acids were selected to investigate the effect of the electrolyte concentration on the solubility of MCFA. The salts were selected taking into account the electrolyte concentrations presented in the gastric fluid, according to the literature (Minekus et al., 2014). Table 1 shows the fatty acids and salts used in this study.

Table 1. Material list

\begin{tabular}{lcl}
\hline Name & CAS code & Supplier \\
\hline Hexanoic acid & $142-62-1$ & Sigma-Aldrich \\
Octanoic acid & $124-07-2$ & Sigma-Aldrich \\
Sodium chloride & $7647-14-5$ & Sigma-Aldrich \\
\hline
\end{tabular}




\section{Potassium chloride 7447-40-7 Sigma-Aldrich \\ Sodium bicarbonate $144-55-8 \quad$ Sigma-Aldrich}

\section{In vitro digestion simulation}

Samples of tributyrin (Sigma-Aldrich, USA), muru-muru butter and Brazil nut oil, both supplied by Amazon Oil Industry (Brazil), were used in the gastrointestinal digestion simulation. While the pure TAG sample is composed by the short-chain fatty acid (SCFA) butyric acid (C4:0), the muru-muru butter is abundant in MCFA, particularly the lauric acid (C12:0). Meanwhile, the Brazil nut oil major component is a LCFA the oleic acid (C18:1), according to the FA compositions reported in a previous publication by our research group (Pereira et al., 2019).

The reagents employed in the simulated gastric fluid (SGF) and simulated intestinal fluid (SIF) preparations can be found in Table 2.

Table 2. Reagents used in the in vitro digestion simulation experiments

\begin{tabular}{lc}
\hline \multicolumn{1}{c}{ Reagent } & Supplier \\
\hline Potassium chloride & Sigma Aldrich \\
Monopotassium phosphate & Sigma Aldrich \\
Sodium bicarbonate & Sigma Aldrich \\
Sodium chloride & Sigma Aldrich \\
\hline
\end{tabular}




\begin{tabular}{lc}
\hline Magnesium chloride & Sigma Aldrich \\
Ammonium carbonate & Sigma Aldrich \\
Chloridric acid & Merk \\
Sodium hydroxide & Vetec \\
Calcium chloride & Sigma Aldrich \\
Pepsin form porcine & Sigma Aldrich \\
Pancreatin & Sigma Aldrich \\
Bile extract & Sigma Aldrich
\end{tabular}

\section{Experimental method}

Liquid-liquid equilibrium behavior

Different mass salt concentrations were tested in this study, as given in Table 3. These concentrations were defined from the suggested concentrations given in the literature for each salt (Minekus et al., 2014). All possible binary mixtures containing the selected FA and electrolyte solutions composed by one of the salts were tested. The components were mixed using a 1:1 mass ratio in equilibrium glass cells connected to a thermostatic bath (Cole Parmer, USA) for temperature control. The compounds were weighed in an analytical balance (XT220A, Precisa, Switzerland, precision de $2 \times 10^{-4}$ ). Then, the samples were stirred vigorously with a magnetic stirrer (Fisatom, Brasil) for 30 min at $37^{\circ} \mathrm{C}$. All systems were left to rest for at least $24 \mathrm{~h}$, to enable phase separation and to ensure the liquid-liquid equilibrium was attained. Samples of both phases were collected in syringes for the components' quantification.

Table 3. Salt concentrations of simulated gastric fluid (Minekus et al., 2014)

\begin{tabular}{ccc}
\hline \multirow{2}{*}{ Sal } & $\begin{array}{c}\text { Fluido } \\
\text { Gástrico } \\
\text { Simulado }\end{array}$ & $\begin{array}{c}\text { Fluido Entérico } \\
\text { Simulado }\end{array}$ \\
\cline { 2 - 3 } & $\mathrm{mmol} / \mathrm{L}$ & $\mathrm{mmol} / \mathrm{L}$ \\
\hline $\mathrm{KCl}$ & 6.9 & 6.8 \\
$\mathrm{KH}_{2} \mathrm{PO}_{4}$ & 0.9 & 0.8 \\
\hline
\end{tabular}




\begin{tabular}{ccc}
\hline $\mathrm{NaHCO}_{3}$ & 25 & 85 \\
$\mathrm{NaCl}$ & 47.2 & 38.4 \\
$\mathrm{MgCl}_{2}\left(\mathrm{H}_{2} \mathrm{O}\right)_{6}$ & 0.1 & 0.33 \\
$\left(\mathrm{NH}_{4}\right)_{2} \mathrm{CO}_{3}$ & 0.5 & 0 \\
\hline
\end{tabular}

Acidity and water contents were determined by titration, using the method 2201 (IUPAC, 1979), and Karl Fischer titration, according to the method Ca 2e-84 (AOCS, 2009) using a KF Titrino plus (model 870, Metrohm, Switzerland). The salt concentrations were calculated by the experimental water concentration, considering the initial concentration of each salt.

\section{In vitro digestion simulation}

The selected method to perform the in vitro digestion experiments is that one described by Minekus et al. (2014). This method is based on three steps. The first step, which simulates the oral digestion, was neglected due to the meaningless content of carbohydrates of the samples evaluated here. The experiments were conducted using equilibrium glass cells connected to a thermostatic bath (Cole-Parmer Polystat, USA) at $37{ }^{\circ} \mathrm{C}$, under stirring with a magnetic stirrer (Fisatom, Brazil) at $200 \mathrm{rpm}$. The gastric digestion was simulated by the addition of the samples, without any previous treatment, SGF, prepared previously according to the protocol described by Minekus et al. (2014), pepsin from porcine at $25.000 \mathrm{U} / \mathrm{ml}$, calcium chloride solution at $0.3 \mathrm{M}$, and chloridiric acid solution $1 \mathrm{M}$ to adjust the $\mathrm{pH}$ at 3.0. During the $120 \mathrm{~min}$, in which the mixture remained under agitation, the mixture $\mathrm{pH}$ was controlled by a $\mathrm{pH}$ meter (Highmed, Brazil). Subsequently, the enteric digestion phase was simulated by the addition of FIS, prepared previously according to the protocol described by Minekus et al. (2014), pancreatin solution at $800 \mathrm{U} / \mathrm{ml}$, calcium chloride solution at $0.3 \mathrm{M}$, and sodium hydroxide solution $1 \mathrm{M}$ to adjust the $\mathrm{pH}$ at 7.0. Once again, the mixture $\mathrm{pH}$ was controlled with the help of a pH meter, and the mixture was maintained under agitation for $120 \mathrm{~min}$. The proportions between samples, simulated fluids, calcium chloride solution, and enzymes can be found in the literature (Minekus et al., 2014).

Two separate in vitro digestion simulation experiments were performed in parallel. At the beginning of the enteric stage, one of the experiments was interrupted, and samples were collected to be analyzed regarding the FFA composition, according to the method 2201 (IUPAC, 1979). The water content of the samples was measured by 
evaporation using a convection forced air chamber (Marconi, Brazil). The concentration of remaining acylglycerols was determined by difference. In this study, all the measurements were performed at least in triplicate.

At this in vitro simulation study, the acidity content total composition of TAGs were determined at the beginning of the enteric digestion stage and at the end of this same digestion phase. The aim of this procedure was to evaluate the lipolysis rate for TAGs containing FA of various carbon chain length. The increasing of acidity content of the samples and decreasing of total TAG content were used to infer about the lipolysis rate of the several lipids evaluated here.

\section{Modeling}

Liquid-liquid equilibrium behavior

The software MATLAB was used for adjusting the binary interaction parameters of the UNIQUAC model, using the experimental equilibrium data for the evaluated systems. The interaction parameters estimation was based on the minimization of the composition objective function (Equation 1), using a modified Simplex method (Nelder $\&$ Mead, 1965).

$$
\mathrm{S}=\sum_{m}^{D} \sum_{n}^{N} \sum_{i}^{C-1}\left[\left(\omega_{i n m}^{O P, \exp }-\omega_{\text {inm }}^{A P, \text { calc }} / \sigma_{\omega_{i n m}^{O P}}\right)^{2}+\left(\omega_{i n m}^{A P, \exp }-\omega_{i n m}^{O P, \text { calc }} / \sigma_{\omega_{i n m}^{A P}}\right)^{2}\right]
$$

Where $D$ is the total numer of data groups; $N$ is the number of concentrations evaluated; $C$ is the total number of components; $\omega$ is mass fraction, and the subscripts $i, n$, and $m$ are component, concentration, and group number, respectively; exp and calc are calculated and experimental compositions; $\sigma$ is the standard deviation observed for the phase compositions; the superscripts $O P$ and AP refers to the oil and aqueous phases, respectively.

Because of the presence of electrolytes, it was necessary use the databank available in the literature for parameters of the ions. Tables 4 and 5 show the UNIQUAC parameters related to the ions volume and area, as well as the functional groups of FAs. The systems were considered as pseudo-ternary [FA + water + salt]. The UNIQUAC parameters for ions and for functional groups were obtained from the literature (Kang et 
al., 2011; Thomsen et al., 1996).

Table 4. Volume and area parameters of the UNIQUAC model for salts

\begin{tabular}{cccc}
\hline Salts & $\mathrm{MM}^{a}$ & $\mathrm{Rk}$ & $\mathrm{Qk}$ \\
\hline $\mathrm{KCl}$ & 74.55 & 12.6164 & 12.6276 \\
$\mathrm{KH}_{2} \mathrm{PO}_{4}$ & 136.086 & 10.5392 & 10.6281 \\
$\mathrm{NaHCO}_{3}$ & 84.0 & 12.4764 & 14.728 \\
$\mathrm{NaCl}$ & 58.44 & 11.7894 & 11.396 \\
$\mathrm{MgCl}_{2}\left(\mathrm{H}_{2} \mathrm{O}\right)_{6}$ & 203.3 & 31.702 & 31.334 \\
$\left(\mathrm{NH}_{4}\right)_{2} \mathrm{CO}_{3}$ & 96.09 & 15.2037 & 15.3718 \\
\hline \multicolumn{4}{c}{$\mathrm{MM}$ molar mass. }
\end{tabular}

Table 5. Volume and area parameters of the UNIQUAC for fatty acids

\begin{tabular}{|c|c|c|c|c|}
\hline \multirow{2}{*}{$\begin{array}{l}\text { Functional } \\
\text { groups }\end{array}$} & \multirow{2}{*}{$\mathrm{Rk}$} & \multirow{2}{*}{ Qk } & \multicolumn{2}{|c|}{ Number of UNIQUAC Groups } \\
\hline & & & Caproic acid & Caprylic acid \\
\hline $\mathrm{CH}_{3}$ & 0.9011 & 0.85 & 1 & 1 \\
\hline $\mathrm{CH}_{2}$ & 0.6744 & 0.54 & 3 & 5 \\
\hline $\mathrm{CH}$ & 0.4469 & 0.23 & 0 & 0 \\
\hline $\mathrm{CH}_{2} \mathrm{COO}$ & 1.6764 & 1.42 & 1 & 1 \\
\hline $\mathrm{CH}=\mathrm{CH}$ & 1.1167 & 0.68 & 0 & 0 \\
\hline
\end{tabular}

\section{Results and discussion}

\section{Liquid-liquid equilibrium behavior}

The experimental data obtained in the LLE study of the systems formed caproic acid and caprylic acid + electrolyte solution are presented in Tables 6 and 7, respectively.

Table 6. Experimental data on the liquid-liquid equilibrium of systems composed by caproic acid (1) + electrolyte solution of potassium chloride, sodium bicarbonate, and sodium chloride (3) at $37{ }^{\circ} \mathrm{C} .100 \mathrm{w}=\%$ mass

\begin{tabular}{|c|c|c|c|c|c|}
\hline Ssolution & $\begin{array}{l}\text { Salt } \\
\text { concentration } \\
\text { of the initial }\end{array}$ & $100 w_{l}{ }^{O P}$ & $100 w_{3} O P$ & $100 w_{l}^{A P}$ & $100 w_{3}{ }^{A P}$ \\
\hline
\end{tabular}




\begin{tabular}{|c|c|c|c|c|c|}
\hline & $\begin{array}{l}\text { mixture (\% } \\
\text { mass) }\end{array}$ & & & & \\
\hline \multirow{4}{*}{$\mathrm{H}_{2} \mathrm{O}+\mathrm{KCl}$} & 0.11 & 83.65 & 16.35 & 0.37 & 99.63 \\
\hline & 0.24 & 85.22 & 14.78 & 0.30 & 99.70 \\
\hline & 0.47 & 87.00 & 13.00 & 0.93 & 99.07 \\
\hline & 1.68 & 90.00 & 10.00 & 1.42 & 98.58 \\
\hline \multirow{4}{*}{$\begin{array}{l}\mathrm{H}_{2} \mathrm{O}+ \\
\mathrm{NaHCO}_{3}\end{array}$} & 0.44 & 85.76 & 14.24 & 0.49 & 99.51 \\
\hline & 0.86 & 83.74 & 16.26 & 0.80 & 99.20 \\
\hline & 1.68 & 79.34 & 20.66 & 0.85 & 99.15 \\
\hline & 6.74 & 66.67 & 33.33 & 1.06 & 98.94 \\
\hline \multirow{3}{*}{$\mathrm{H}_{2} \mathrm{O}+\mathrm{NaCl}$} & 0.56 & 83.95 & 16.05 & 0.71 & 99.29 \\
\hline & 2.23 & 86.65 & 13.35 & 1.03 & 98.97 \\
\hline & 8.94 & 89.00 & 11.00 & 0.48 & 99.52 \\
\hline
\end{tabular}

Table 7. Experimental data on the liquid-liquid equilibrium of systems composed by caprylic acid (2) + electrolyte solution of potassium chloride, sodium bicarbonate, and sodium chloride $(3)$ at $37^{\circ} \mathrm{C} .100 \mathrm{w}=\%$ mass

\begin{tabular}{|c|c|c|c|c|c|}
\hline Solution & $\begin{array}{l}\text { Salt } \\
\text { concentration } \\
\text { of the initial }\end{array}$ & $100 w_{2}{ }^{O P}$ & $100 w_{3} O P$ & $100 w_{2}^{A P}$ & $100 w 3^{A P}$ \\
\hline
\end{tabular}




\begin{tabular}{|c|c|c|c|c|c|}
\hline & $\begin{array}{l}\text { mixture (\% } \\
\text { mass) }\end{array}$ & & & & \\
\hline \multirow{4}{*}{$\mathrm{H}_{2} \mathrm{O}+\mathrm{KCl}$} & 0,11 & 87,49 & 12,51 & 0,30 & 99,70 \\
\hline & 0,24 & 88,41 & 11,59 & 0,28 & 99,72 \\
\hline & 0,47 & 90,81 & 9,19 & 0,29 & 99,71 \\
\hline & 1,68 & 95,49 & 4,51 & 0,31 & 99,69 \\
\hline \multirow{3}{*}{$\begin{array}{l}\mathrm{H}_{2} \mathrm{O}+ \\
\mathrm{NaHCO}_{3}\end{array}$} & 0,86 & 83,74 & 16,26 & 0,80 & 99,20 \\
\hline & 1,68 & 85,83 & 14,17 & 0,29 & 99,71 \\
\hline & 6,74 & 88,00 & 12,00 & 0,32 & 99,68 \\
\hline \multirow{3}{*}{$\begin{array}{l}\mathrm{H}_{2} \mathrm{O}+ \\
\mathrm{NaCl}\end{array}$} & 0,56 & 88,80 & 11,20 & 0,26 & 99,74 \\
\hline & 2,23 & 90,39 & 9,61 & 0,29 & 99,71 \\
\hline & 8,94 & 98,91 & 1,09 & 0,00 & 100,00 \\
\hline
\end{tabular}

The experimental data obtained for the systems evaluated here showed that, in general, the addition of electrolyte to the solvent phase decreased the mutual solubility of the system, particularly in the oil phase. Considering that the FA diffusion is affected by the ionic strength of the electrolyte present in the aqueous solution, the addition of those components should decrease the solubility of the phases. As one may notice, this pattern was observed in the experimental results shown in Figure 1. It can be observed in Figure 1 that only the systems composed by caproic acid + aqueous solutions of sodium bicarbonate presented the inverse trend behavior from that observed in the other systems. 

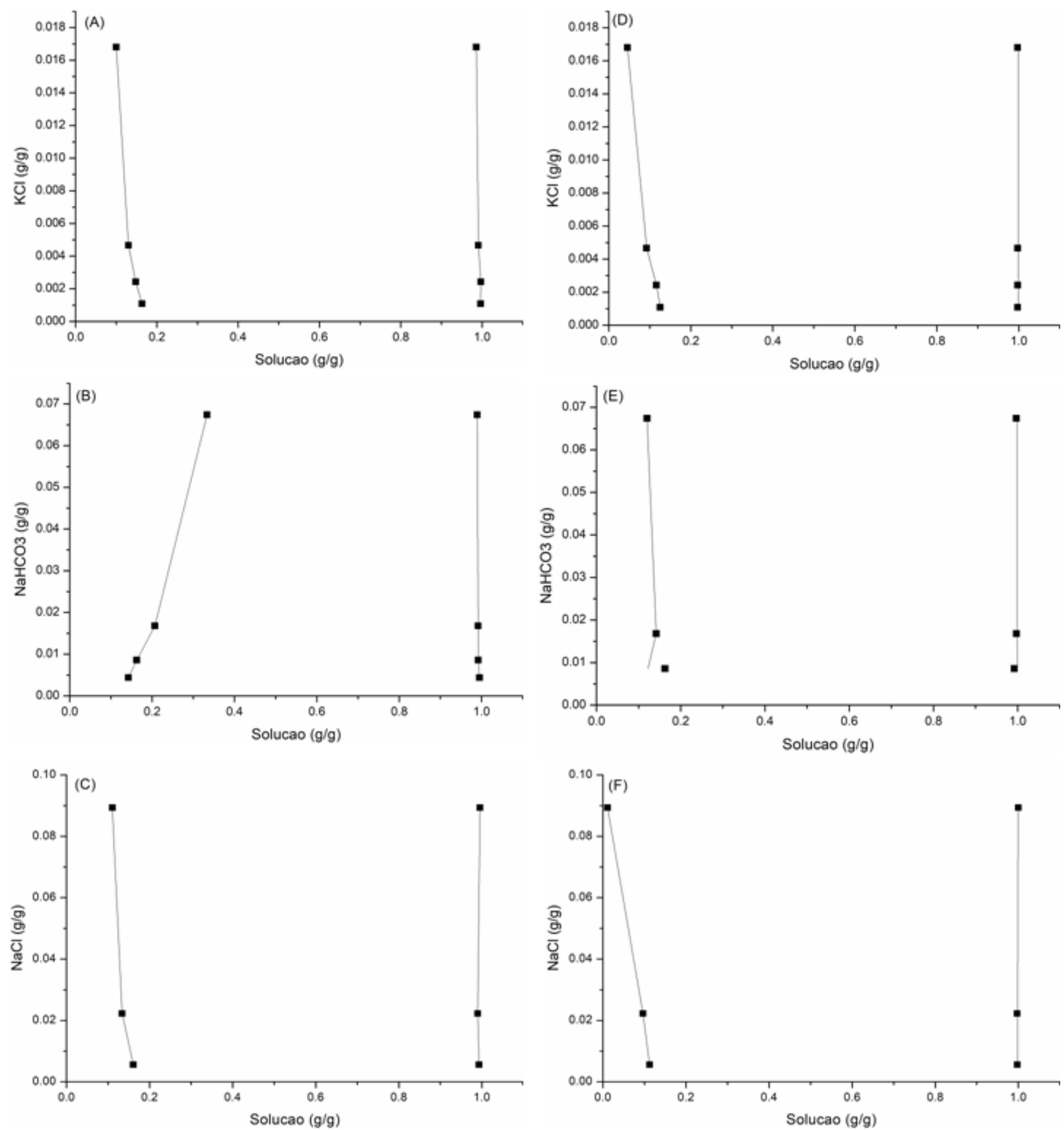

Figure 1. Experimental and predicted electrolyte concentration - aqueous solution concentration diagrams at $37^{\circ} \mathrm{C}$ : (A) caproic acid + potassium chloride; (B) caproic acid + sodium bicarbonate; (C) caproic acid + sodium chloride; (D) caprylic acid + potassium chloride; $(\mathrm{E})$ caprylic acid + sodium bicarbonate; $(\mathrm{F})$ caprylic acid + sodium chloride. $(\bullet)$ experimental data; $(---)$ UNIQUAC.

The UNIQUAC model with the adjutsted binary interaction parameters (Table 8) correlated satisfactorily the experimental data, being able of describing the effect of the 
electrolyte concentrations of the systems. Moreover, the model described the experimental mass cocentrations with an overall deviation of $0.13 \%$.

Table 8. Adjusted binary interaction parameters of the UNIQUAC model. Components:

(1) caproic acid; (2) caprylic acid; $(3,6,8,11) \mathrm{KCl}$ solutions at 13.8, 27.6, 53.2, and $106.4 \mathrm{mM}$, respectively; $(5,10,13) \mathrm{NaHCO}_{3}$ solutions at 50, 100, 200, and $400 \mathrm{mM}$, respectively; $(4,7,9,12) \mathrm{NaCl}$ solutions at $47.2,94.4,188.8$, and $377.6 \mathrm{mM}$, respectively

\begin{tabular}{cccccc}
\hline Pair $i j$ & $A_{i j} \times 10^{4}$ & $A_{j i} \times 10^{4}$ & Pair $i j$ & $A_{i j} \times 10^{4}$ & $A_{j i} \times 10^{4}$ \\
\hline $1-3$ & 4.01 & 1.63 & $2-3$ & 4.06 & 2.08 \\
$1-4$ & 2.97 & 0.86 & $2-4$ & - & - \\
$1-5$ & 2.14 & -0.32 & $2-5$ & 1.56 & 1.19 \\
$1-6$ & 2.66 & -1.40 & $2-6$ & 2.02 & 2.03 \\
$1-7$ & 1.89 & 0.43 & $2-7$ & 1.15 & 1.02 \\
$1-8$ & 0.58 & 1.97 & $2-8$ & 1.28 & 1.11 \\
$1-9$ & 1.01 & -0.10 & $2-9$ & 1.14 & 0.48 \\
$1-10$ & 0.70 & 2.49 & $2-10$ & 3.34 & -1.12 \\
$1-11$ & 1.18 & 1.26 & $2-11$ & 3.06 & -0.43 \\
$1-12$ & -2.92 & 1.60 & $2-12$ & 0.06 & -1.44 \\
$1-13$ & -1.67 & -0.89 & $2-13$ & -2.34 & 1.08 \\
\hline
\end{tabular}

As one may notice from Figure 1 and the overall deviation between predicted and experimental results, the use of conventional UNIQUAC was satisfactory to describe the effect of several electrolyte concentrations on the systems. Hence, the use of more complex modeling approaches, considering the presence of ions, was not found to be critical. This class of sophisticated modeling approaches tends to decrease the flexibility of the modeling method and demands the inclusion of structural parameters related to the salt ions and water molecules.

Therefore, the comparison of the LLE behavior of several systems containing MCFA and electrolyte solutions showed that the increasing of electrolyte concentrations tend to decrease the mutual solubility of the systems (Figure 1). These obtained results 
are in agreement with the literature and can be explained by the increase of the ionic strength of the mixture, which limits the solubility of the FAs. It worth noting that electrolyte concentrations evaluated here are superior to those usually found in the gastric fluid. Thus, the results obtained here suggest that the ingestion of salts, such as those evaluated in this study, tends to decrease the FA solubility in the gastric fluid.

\section{Results and discussion}

In vitro digestion simulation

Table 10 shows the obtained results for the in vitro digestion simulation experiments.

Table 10. Free fatty acids, water, salts, and enzyme contents of triglyceride samples submitted to the in vitro digestion simulation

\begin{tabular}{|c|c|c|c|c|c|c|c|c|}
\hline \multirow[t]{2}{*}{ Sample } & \multicolumn{2}{|c|}{$\begin{array}{l}\text { Free fatty acids } \\
\qquad(\mathrm{m} / \mathrm{m})\end{array}$} & \multicolumn{2}{|c|}{ Water $(\mathrm{m} / \mathrm{m})$} & \multicolumn{2}{|c|}{$\begin{array}{c}\text { Salts and } \\
\text { enzymes }(\mathrm{m} / \mathrm{m})\end{array}$} & \multicolumn{2}{|c|}{$\begin{array}{c}\text { TAG/DAG/MAG } \\
(\mathrm{m} / \mathrm{m})\end{array}$} \\
\hline & Initial & Final & Initial & Final & Initial & Final & Initial & Final \\
\hline Tributyrin & 0.0304 & 0.0937 & 0.9587 & 0.8969 & 0.0002 & 0.0002 & 0.0107 & 0.0092 \\
\hline $\begin{array}{l}\text { Muru- } \\
\text { muru }\end{array}$ & 0.0169 & 0.0205 & 0.6700 & 0.6600 & 0.0002 & 0.0002 & 0.3347 & 0.3164 \\
\hline Brazil nut & 0.0257 & 0.0286 & 0.6400 & 0.6300 & 0.0002 & 0.0002 & 0.3615 & 0.3438 \\
\hline
\end{tabular}

It can be seen from Table 10 that the increases in acidity content between the initial and final point of the enteric digestion simulation stage were distinct for each lipid sample evaluated here. In the experiment performed with tributyrin, the increase in acidity content was $67.56 \%$. Meanwhile, the muru-muru butter and Brazil nut oil experiments displayed acidity content increases of $17.56 \%$ and $10.14 \%$, respectively. These results indicate that the action of the pancreatic enzyme, promoter of the lipolysis reaction, occurred preferentially in TAG molecules comprised by SCFA (C4:0) from the tributyrin sample. Taking into account only the fat and oil samples evaluated here, it can be observed that the lipolysis rate of the muru-muru sample, comprised majorly by MCFA (C12:0), was superior than that observed for the Brazil nut oil, which the major FA is the oleic acid (C18:1) a LCFA. 
These results can be explained by the specificity of the pancreatic lipase for the $s n-1$ and $s n-3$ positions of the glycerol backbone and its higher activity for SCFA and MCFA, which are rapidly hydrolyzed by this enzyme (Singh \& Gallier, 2013).

Accordingly, considering the results presented here, it can be inferred that the lipolysis took place at distinct rates, and the enzyme activity is higher in TAG molecules comprised by FA of short and medium chains, when compared against those molecules composed by LCFA. However, because the utilization of the gastric lipase is not comprehended in the protocol adopted in these experiments, it could not been elucidated in the present study what is its influence on the lipolysis rate during the gastric digestion phase. It is known that from 5 to $40 \%$ of dietetic triglycerides are hydrolyzed by the gastric lipase in the stomach, and this enzyme has also a preferential activity for SCFA and MCFA in the $s n-1$ and $s n-3$ of the glycerol backbone (Gallier \& Singh, 2012a).

Nevertheless, this present study casts new light on the fat digestion process, since it shows that the activity of the pancreatic lipase is inversely proportional to the carbon chain length of the FA molecules components of the triglyceride.

\section{Acknowledgments}

Ericsem Pereira thanks the São Paulo Research Foundation (FAPESP) (2017/16979-7) for the scholarship and financial support. The authors thank the national funding agencies FAPESP (2014/2152-0 and 2016/08566-1) and the National Council for Scientific and Technological Development (CNPq) (305870/2014-9 and 406963/2016-9) for their financial support and scholarships. This study was also financed in part by the Coordenação de Aperfeiçoamento de Pessoal de Nível Superior e Brasil (CAPES) e Finance Code 001.

\section{References}

AOCS. (2009). Official Methods and Recommended Practices of the AOCS (D.

Firestone (ed.); 6th ed.). American Oil Chemists' Society.

Armand, M., Pasquier, B., André, M., Borel, P., Senft, M., Peyrot, J., Salducci, J., Portugal, H., Jaussan, V., \& Lairon, D. (1999). Digestion and absorption of 2 fat emulsions with different droplet sizes in the human digestive tract. The American Journal of Clinical Nutrition, 70(6), 1096-1106. 
https://doi.org/10.1093/ajcn/70.6.1096

Ayala-Bribiesca, E., Turgeon, S. L., \& Britten, M. (2017). Effect of calcium on fatty acid bioaccessibility during in vitro digestion of Cheddar-type cheeses prepared with different milk fat fractions. Journal of Dairy Science, 100(4), 2454-2470. https://doi.org/10.3168/jds.2016-11902

Bakala-N'Goma, J. C., Williams, H. D., Sassene, P. J., Kleberg, K., Calderone, M., Jannin, V., Igonin, A., Partheil, A., Marchaud, D., Jule, E., Vertommen, J., Maio, M., Blundell, R., Benameur, H., Müllertz, A., Pouton, C. W., Porter, C. J. H., \& Carrière, F. (2015). Toward the establishment of standardized in vitro tests for lipid-based formulations. 5. lipolysis of representative formulations by gastric lipase. Pharmaceutical Research, 32(4), 1279-1287. https://doi.org/10.1007/s11095-014-1532-y

Barker, R., Abrahamsson, B., \& Kruusmägi, M. (2014). Application and Validation of an Advanced Gastrointestinal In Vitro Model for the Evaluation of Drug Product Performance in Pharmaceutical Development. Journal of Pharmaceutical Sciences, 103(11), 3704-3712. https://doi.org/10.1002/jps.24177

Bernbäck, S., Bläckberg, L., \& Hernell, O. (1989). Fatty acids generated by gastric lipase promote human milk triacylglycerol digestion by pancreatic colipasedependent lipase. Biochimica et Biophysica Acta (BBA) - Lipids and Lipid Metabolism, 1001(3), 286-293. https://doi.org/10.1016/0005-2760(89)90113-6

Charlton, S. C., \& Smith, L. C. (1982). Kinetics of transfer of pyrene and rac-1-oleyl-2[4-(3-pyrenyl)butanoyl]glycerol between human plasma lipoproteins. Biochemistry, 21(17), 4023-4030. https://doi.org/10.1021/bi00260a018

Cistola, D. P., Hamilton, J. A., Jackson, D., \& Small, D. M. (1988). Ionization and phase behavior of fatty acids in water: application of the Gibbs phase rule. Biochemistry, 27(6), 1881-1888. https://doi.org/10.1021/bi00406a013

Devraj, R., Williams, H. D., Warren, D. B., Mullertz, A., Porter, C. J. H., \& Pouton, C. W. (2013). In vitro digestion testing of lipid-based delivery systems: Calcium ions combine with fatty acids liberated from triglyceride rich lipid solutions to form soaps and reduce the solubilization capacity of colloidal digestion products. 
International Journal of Pharmaceutics, 441(1-2), 323-333.

https://doi.org/10.1016/j.ijpharm.2012.11.024

Gallier, S., \& Singh, H. (2012a). Behavior of almond oil bodies during in vitro gastric and intestinal digestion. Food \& Function, 3(5), 547.

https://doi.org/10.1039/c2fo10259e

Gallier, S., \& Singh, H. (2012b). The physical and chemical structure of lipids in relation to digestion and absorption. Lipid Technology, 24(12), 271-273.

https://doi.org/10.1002/lite.201200240

Hofmann, A. F. (1976). Fat Digestion: The Interaction of Lipid Digestion Products with Micellar Bile Acid Solutions. In Lipid Absorption: Biochemical and Clinical Aspects (pp. 3-21). Springer Netherlands. https://doi.org/10.1007/978-94-0117176-2_1

IUPAC. (1979). Determination of the Acid Value (A. V.) and the Acidity. In C. Paquot (Ed.), Standard Methods for the Analysis of Oils, Fats and Derivatives (6th ed., Issue note 2, pp. 52-55). Elsevier. https://doi.org/10.1016/B978-0-08-0223797.50021-8

IUPAC. (1991). Standard methods for the analysis of oils, fats and derivatives. In A.Dieffenbacher \& W. D. Pocklington (Eds.), International Union of Pure and Applied Chemistry Applied Chemistry Division Commission on Oils, Fats and Derivatives (7th ed.). Blackwell Scientific Publications.

https://doi.org/10.1351/pac198254061257

Kang, J. W., Diky, V., Chirico, R. D., Magee, J. W., Muzny, C. D., Abdulagatov, I., Kazakov, A. F., \& Frenkel, M. (2011). A new method for evaluation of UNIFAC interaction parameters. Fluid Phase Equilibria, 309(1), 68-75.

https://doi.org/10.1016/J.FLUID.2011.07.001

Koziolek, M., Carrière, F., \& Porter, C. J. H. (2018). Lipids in the Stomach Implications for the Evaluation of Food Effects on Oral Drug Absorption. Pharmaceutical Research, 35(3). https://doi.org/10.1007/s11095-017-2289-x

Mattson, F. H., \& Volpenhein, R. A. (1964). The Digestion and Absorption of Triglycerides. The Journal of Biological Chemistry, 239, 2772-2777. 
Minekus, M., Alminger, M., Alvito, P., Ballance, S., Bohn, T., Bourlieu, C., Carrière, F., Boutrou, R., Corredig, M., Dupont, D., Dufour, C., Egger, L., Golding, M., Karakaya, S., Kirkhus, B., Le Feunteun, S., Lesmes, U., Macierzanka, A., Mackie, A., ... Brodkorb, A. (2014). A standardised static in vitro digestion method suitable for food - an international consensus. Food \& Function, 5, 1113-1124. https://doi.org/10.1039/c3fo60702j

Nelder, J. A., \& Mead, R. (1965). A Simplex Method for Function Minimization. The Computer Journal, 7(4), 308-313. https://doi.org/10.1093/comjn1/7.4.308

Pereira, E., Ferreira, M. C., Sampaio, K. A., Grimaldi, R., Meirelles, A. J. de A., \& Maximo, G. J. (2019). Physical properties of Amazonian fats and oils and their blends. Food Chemistry, 278(October 2018), 208-215. https://doi.org/10.1016/j.foodchem.2018.11.016

Phan, S., Salentinig, S., Gilbert, E., Darwish, T. A., Hawley, A., Nixon-Luke, R., Bryant, G., \& Boyd, B. J. (2015). Disposition and crystallization of saturated fatty acid in mixed micelles of relevance to lipid digestion. Journal of Colloid and Interface Science, 449, 160-166. https://doi.org/10.1016/j.jcis.2014.11.026

Shiau, Y. F. (1990). Mechanism of intestinal fatty acid uptake in the rat: the role of an acidic microclimate. The Journal of Physiology, 421(1), 463-474. https://doi.org/10.1113/jphysiol.1990.sp017955

Singh, H., \& Gallier, S. (2013). Understanding Lipid Structures and Digestibility. International News on Fats, Oils, and Related Materials, 24(3), 134-140.

Singh, H., Ye, A., \& Horne, D. (2009). Structuring food emulsions in the gastrointestinal tract to modify lipid digestion. Progress in Lipid Research, 48(2), 92-100. https://doi.org/10.1016/j.plipres.2008.12.001

Thomsen, K., Rasmussen, P., \& Gani, R. (1996). Correlation and prediction of thermal properties and phase behaviour for a class of aqueous electrolyte systems. Chemical Engineering Science, 51(14), 3675-3683. https://doi.org/10.1016/00092509(95)00418-1

Toro-Vazquez, J. F., García-L, O. E., \& Guerrero-E, L. L. (1991). Adsorption isotherms of squash (Cucurbita moschata) seed oil on activated carbon. Journal of the 
American Oil Chemists Society, 68(8), 596-599.

https://doi.org/10.1007/BF02660160

Williams, H. D., Sassene, P., Kleberg, K., Calderone, M., Igonin, A., Jule, E., Vertommen, J., Blundell, R., Benameur, H., Müllertz, A., Pouton, C. W., \& Porter, C. J. H. (2013). Toward the Establishment of Standardized In Vitro Tests for Lipid-Based Formulations, Part 3: Understanding Supersaturation Versus Precipitation Potential During the In Vitro Digestion of Type I, II, IIIA, IIIB and IV Lipid-Based Formulations. Pharmaceutical Research, 30(12), 3059-3076. https://doi.org/10.1007/s11095-013-1038-z 